\title{
Peningkatan Kualitas Pengiriman Barang Melalui Sistem Door To Door
}

\author{
Nuryanto $^{{ }^{*}}$, Elyatuzaka ${ }^{2}$, Anggit Ridho ${ }^{3}$ \\ 1,2,3 Universitas Maritim AMNI Semarang, Jl. Sukarno - Hatta Semarang, Indonesia \\ *Corresponding Author. E-mail : nuryanto.amni@gmail.com.Telp : 08122515006
}

\begin{abstract}
Abstrak
Dalam proses pengadaan barang, berbagai kegiatan harus dilalui. Mulai dari lokasi dimana bahan baku itu dihasilkan diangkut ketempat pengolahan untuk menjadikannya bahan jadi yang selanjutnya didistribusikan kepada pelanggan yang tersebar diberbagai tempat harus dilakukan melalui secara efisien, tepat manfaat dalam waktu yang singkat agar harga produk dapat terjangkau oleh konsumen. Dengan demikian peran perusahaan pelayaran sangat penting untuk menunjang distribusi barang dan jasa dari satu tempat ke tempat yang lain. PT Salam Pacific Indonesia Lines (PT SPIL) Cabang Pontianak, merupakan salah satu industri pelayaran nasional yang menyediakan jasa pengiriman barang dengan pelayanan logistik sistem door to door, telah melayani hampir seluruh pulau di Indonesia. Penelitian ini bertujuan untuk mengetahui peran dan tanggung jawab SPIL Cabang Pontianak dalam pelayanan pengiriman barang sistem door to door, dengan menggunakan metode deskriptif yang memusatkan perhatian pada masalah masalah aktual apa adanya, diperoleh gambaran bahwa PT SPIL Cabang Pontianak menerapkan empat area logistik dalam aktivitas logistiknya, dengan sistem door to door service. Empat area logistik tersebut yakni order processing, transportation, material handling, dan facility network design.
\end{abstract}

Kata Kunci : Pengiriman, Peningkatan Kualitas, Sistem Door To Door

\begin{abstract}
There are various activities carried out in the process of procurement of goods. It is started from the location where the raw material is produced and transported to the processing location and produce it as a finished product. Subsequently, that product is distributed to customers in various places. This distribution must be efficiently and precisely carried out in a short time therefore the price of the product can be affordable by consumers. Hence, the role of shipping lines is very important to support the distribution of goods and services from one place to another. PT Salam Pacific Indonesia Lines (PT SPIL) Pontianak Branch, is one of the national shipping industry that provides freight forwarding services with door to door system logistics services. Furthermore, its service is almost all islands in Indonesia. This research aims at finding out the role and responsibility of SPIL Pontianak Branch in the service of shipping goods applying door to door system. It employs descriptive method focusing on the actual problem. This research resulted that PT SPIL Pontianak Branch applies four logistics areas in its logistics activities, with a door to door service system. The four logistics areas are order processing, transportation, material handling, and network design facility.
\end{abstract}


Keywords: Door To Door System, Shipping, Quality Improvement

\section{PENDAHULUAN}

Perkembangan penduduk di Indonesia yang sangat pesat mengakibatkan meningkatnya pertumbuhan ekonomi. Hal ini menyebabkan persaingan antar perusahaan semakin ketat dalam usaha untuk memasarkan barang atau jasa kepada konsumen. Pemasaran produk maupun jasa merupakan salah satu aspek kegiatan yang sangat penting untuk memperkenalkan perusahaan tersebut untuk memperoleh pelanggan dan keuntungan usaha, dengan cara memperbaiki kualitas produk maupun jasanya. Dalam proses pengadaan barang, berbagai kegiatan harus dilalui. Mulai dari lokasi dimana bahan baku itu dihasilkan diangkut ketempat pengolahan untuk menjadikannya bahan jadi yang selanjutnya didistribusikan kepada pelanggan yang tersebar diberbagai tempat harus dilakukan melalui secara efisien, tepat manfaat dalam waktu yang singkat agar harga produk dapat terjangkau oleh konsumen. Dalam proses pengiriman barang ada beberapa sistem atau konsep pengiriman, salah satunya adalah sistem door to door. Menurut Apriani \& Nurasmi (2020) pengertian sistem door to door adalah pengiriman barang dari alamat pengirim menuju alamat tujuan. Dalam kegiatan ini biasa disebut dengan istilah logistik atau pengiriman barang, yang tidak terlepas dengan peran perusahaan pelayaran.

Peran perusahaan pelayaran sangat penting untuk mendukung distribusi barang dan jasa dari satu tempat ke tempat yang lain. Peran angkutan menggunakan kapal laut sangat penting di wilayah Kepulauan Indonesia, karena pengangkutan barang melalui angkutan kapal laut mempunyai kelebihan antara lain : kapasitas muatan yang sangat besar. Hampir semua pengiriman barang ekspor, impor dan muatan lain dengan jumlah yang besar diangkut melalui jalur laut menggunakan kapal. Hampir 95\% kegiatan pengiriman barang menggunakan jasa kapal laut menggunakan petikemas atau container dari suatu daerah ke daerah tujuan, karena kegiatan ini sangat efisien dan dijamin untuk keamanannya karena lebih menguntungkan dengan kapasitas muatan besar dan biaya yang lebih murah (Hutapea, 2019)

PT Salam Pacific Indonesia Lines (PT SPIL) cabang Pontianak bergerak dalam bidang pelayaran yang menyediakan jasa pengiriman barang dengan menggunakan transportasi laut di seluruh Indonesia. Dalam rangka untuk memenuhi keinginan pelanggan, PT. Salam Pacific Indonesia Lines cabang Pontianak memperluas bidangnya yang semula pengiriman barang dari pelabuhan ke pelabuhan lain, kini sudah ada pengiriman dari gudang sampai ke gudang, sehingga memudahkan pelanggan untuk melaksanakan pengiriman barang. Untuk itu PT. Salam Pacific Indonesia Lines membuka Divisi baru, yaitu SPIL Log atau bisa disebut SPIL Logistik, yang bertugas untuk mengurus sebuah pengiriman barang pelanggan dari gudang pengirim sampai ke gudang penerima barang. Dari kegiatan tersebut terbitlah dokumen-dokumen yang wajib diurus ketika mau melakukan pengiriman barang. Untuk itulah SPIL Logistik mempunyai aplikasi khusus untuk memonitor barang pelanggan dan memastikan barang tersebut aman dan sampai ke tujuan. 
Selain itu dokumen barang dikirimkan oleh SPIL Logistik kepada Kantor Cabang untuk dilakukan cek ulang kesesuaian dokumen dan barang. Pada tahun 2017, PT SPIL memunculkan platform digital pertama dengan nama mySPIL Digital Logistic Platform yang didesain secara spesifik oleh PT Salam Pacific Indonesia Lines (SPIL) ini diciptakan untuk memberikan layanan digital yang mudah dan terintergerasi secara online untuk para relasi. My SPIL menjadi aplikasi digital logistik pertama yang berada di Indonesia, menerapkan sistem digitalisasi untuk pemesanan dan pengecekan kontainer via Aplikasi dan Website. Beberapa fitur dari aplikasi my SPIL : Vessel Schedule, On Line Pricing, Booking, Contract and quote, e-SI, e-BL, e-DO, e-Payment, myDashboard, track and Trace, Smart Notification, My SPIL Points(SPILL, 2021).

Logistik adalah seni dan ilmu, barang, energi, informasi, dan sumberdaya lainnya, seperti produk, jasa, dan manusia dari sumber produksi ke pasar dengan tujuan mengoptimal kan penggunaan modal (Kasengkang, 2016). Logistik adalah bagian dari proses manajemen rantai pasokan (Supply Chain Management) yang merencanakan, mewujudkan dan mengendalikan efisiensi dan efektifitas aliran dan penyimpanan barang dan jasa dan informasi antara titik konsumsi untuk memenuhi kebutuhan pelanggan (Hayati, 2014). Hasan et al. (2020) mengatakan logistik adalah seni mengontrol rantai pasok global dengan mengombinasikan transportasi, keahlian pergudangan, manajemen distribusi dan teknologi informasi. Logistik dalam hal ini mencakup dari bagian fungsional, seperti transportasi, warehousing (penyimpanan di gudang), inventory, pertambahan nilai manajemen.

Logistik menurut Council of Supply Chain Management Professionals pada Wilson (2005) adalah bagian dari manajemen rantai pasok (supply chain) dalam perencanaan, pengimplementasian, dan pengontrolan aliran dan penyimpanan barang, informasi, dan pelayanan yang efektif dan efisien dari titik asal ke titik tujuan sesuai dengan permintaan konsumen. Untuk mengalirkan barang dari titik asal menuju titik tujuan akan membutuhkan beberapa aktivitas yang dikenal dengan 'aktivitas kunci dalam logistik' diantaranya: 1) customer service, 2) demand forecasting/planning, 3) inventory management, 4) logistics communications, 5) material handling, 6) traffic and transportation, dan 7) warehousing and storage (Lambert, 2008). Menurut Siregar (2018) bahwa logistik merupakan bagian supply chain management yang berfokus kepada perpindahan barang ataupun penyimpanan barang dan informasi untuk memenuhi kebutuhan pelanggan. Dalam perkembangannya, persepsi tentang logistik berubah, logistik diperepsikan bukan lagi suatu barang yang dibutuhkan, tetapi proses mengadakan barang kebutuhan tersebut dipersepsikan sebagai logistic.

Dalam Cetak Biru Pengembangan Sistem Logistik Nasional (2012) Logistik didefinisikan sebagai bagian dari rantai pasok (supply chain) yang menangani arus barang, informasi, dan uang melalui proses pengadaan (procurement), penyimpanan (warehousing),transportasi(transportation),distribusi (distribution), dan pelayanan pengantaran (delivery services). Adapun penyusunan sistem logistik ditujukan untuk meningkatkan keamanan, efisiensi, dan efektfitas pergerakan barang, informasi, dan uang mulai dari titik asal (point of origin) sampai dengan titik tujuan (point of destination) sesuai dengan jenis, kualitas, jumlah, waktu dan tempat yang dikehendaki konsumen. 
Aktivitas Logistik dapat dibedakan menjadi 3 yaitu inbound logistics, conversion operations dan outbound logistics. Menurut Pokharel (2005) inbound logistics merupakan pergerakan ke dalam perusahaan yang menujukkan aliran material dari pemasok ke pabrik atau dinas operasi. Conversion operations meliputi pergerakan produk di dalam pabrik atau fasilitas pergudangan yang menunjukkan bagaimana barang dan material bergerak di antara fasilitas-fasilitas perusahaan, sedangkan outbond logistics merupakan pergerakan produk keluar pabrik atau dinas operasi menuju ke pelangggan atau konsumen. Fokus yang terjadi pada inbound logistic adalah vendor menyediakan bahan baku dan supplier untuk produk jadi. Dari perspektif inbound logistic ada tiga faktor yang mempengaruhi kinerja, yaitu biaya, kecepatan dan konsistensi pengiriman (Bowersox \& Closs, 1997). Outbound logistic adalah untuk memenuhi permintaan dari konsumen akhir (Coyle \& Bardi, 2003).

Logistik merupakan bagian supply chain management yang berfokus kepada perpindahan barang ataupun penyimpanan barang dan informasi, melalui proses pengadaan (procurement), penyimpanan (warehousing), transportasi (transportation), distribusi (distribution), dan pelayanan pengantaran (delivery services). untuk memenuhi kebutuhan pelanggan. Istilah atau sistem dalam logistik, yaitu : door to door, port to port, door to port dan port to door, sebagaimana telah disebutkan diatas. Dalam hal ini, sistem door to door ada dua proses yaitu proses inbound (muatan) dan outbond (bongkaran). Outbound logistik berarti mengangkut produk jadi dari bisnis ke pelanggan. Jaringan outbound logistic biasanya mencakup banyak mitra - produsen, distributor, pengecer, dan tim transportasi. Jika produsen menyelesaikan produk, maka produk akan diserahkan ke distributor atau langsung ke pelanggan melalui toko eceran. Proses distribusi outbound dikembangkan berdasarkan permintaan konsumen dengan menyediakan barang tepat waktu. Ada perusahaan yang mengirimkan produk langsung ke pelanggan berdasarkan pesanan, dan ada juga perusahaan yang mempekerjakan distributor besar dan pusat pelaksanaan yang menggunakan perusahaan telekomunikasi atau operator swasta.

Mengoptimalkan logistik outbound dapat mengalami kesulitan karena bergantung pada perubahan pasar dan permintaan pelanggan secara terus menerus. Manajer juga harus mempertimbangkan jumlah jenis produk dan distributor untuk merencanakan pengiriman yang akurat. Tidak seperti inbound logistik, outbound menangani produk akhir, yang mungkin lebih rentan daripada bahan mentah, sehingga memerlukan perhatian khusus dari perusahaan pengiriman. Ini mungkin memerlukan biaya kemasan tambahan untuk memastikan barang aman dan transportasi yang aman. Logistik outbound bertanggung jawab oleh manajer yang mengkoordinasikan pengiriman antara produsen dan pelanggan, sehingga memerlukan berbagai manajemen transportasi. Manajer logistik harus menangani pengiriman ke berbagai tujuan, karena perusahaan dapat menandatangani kontrak dengan mitra seperti beberapa toko, distributor e-commerce, dan distributor. Ada juga tekanan bagi pembeli online untuk menyediakan pengiriman yang cepat karena mereka mengharapkan pengiriman yang cepat. Perusahaan dapat mengurangi biaya penyimpanan dan pengiriman, dengan menentukan waktu pengiriman yang paling tepat dan mengoptimalkan proses distribusi outbound. Tanpa pengelolaan distribusi 
outbound yang tepat, pengiriman yang tertunda dapat mempengaruhi hubungan pembeli.

Dalam hal ini, PT SPIL Cabang Pontianak melalui divisi barunya yaitu PT SPIL Logistik bergerak dibidang logistik dengan sistem door to door, mempunyai tujuan untuk meningkatkan kualitas pengiriman barang. Penelitian yang dilakukan oleh Eviani \& Hidayat (2021) memperoleh bukti bahwa ketepatan waktu pengiriman berpengaruh positif dan signifikan terhadap kepuasan pelanggan J\&T Express cabang Kota Baru Bekasi, yang dapat diartikan semakin tepat waktu perusahaan memenuhi janjinya dalam melakukan pengiriman barang maka semakin baik juga kepuasan pelanggan. Penelitian yang dilakukan oleh Rohman \& Abdul (2021) memperoleh bukti bahwa variabel Kualitas Pelayanan $\left(\mathrm{X}_{1}\right)$ dan variabel Ketepatan Pengiriman $\left(\mathrm{X}_{2}\right)$ berpengaruh terhadap Kepuasan Pelanggan (Y) dengan nilai sebesar 41,2\%. Penelitian oleh Mamahit et al. (2021), menyimpulkan bahwa distribusi yang efisien dan efektif, sangat ditentukan oleh : perbaikan infrastruktur. Sedangkan harmonisasi peraturan menempati urutan kedua. Selanjutnya penghapusan biaya tidak resmi, penegakan hukum dan peningkatan SDM berada pada urutan berikutnya

Sejalan dengan beberapa penelitian diatas, dapat disimpulkan bahwa : semakin tepat waktu pengiriman dan peningkatan kualitas pelayanan dapat mempengaruhi kepuasan pelanggan. Disamping distribusi yang efisien dan efektif, sangat ditentukan oleh perbaikan infrastruktur. Dari hasil penelitian ini diharapkan bahwa dengan pengiriman secara door to door, dapat menjaga ketepatan waktu pengiriman untuk meningkatkan kualitas pelayanan, dengan tujuan akhirnya adalah kepuasan pelanggan(Widyanto, 2018). Berdasarkan latar belakang tersebut diatas, peneliti berkeinginan membahas lebih dalam tentang bagaimana PT SPIL Logistik Cabang Pontianak dalam memberikan pelayanan pengiriman barang secara door to door service, sehingga diharapkan dapat meningkatkan kualitas pengiriman barang.

\section{METODE PENELITIAN}

Penelitian ini dilakukan pada PT SPIL Logitik Cabang Pontianak. Adapun jenis data yang dipergunakan dalam penelitian ini adalah data primer dan data sekunder (Situmorang et al., 2010). Menurut Martono dalam Astriawati (2020) data primer adalah data yang diperoleh langsung oleh pengumpul data dari objek penelitiannya. Data primer pada penelitian ini diperoleh dari hasil observasi atau hasil kerja lapangan yang juga dilengkapi dengan hasil wawancara dengan berbagai pihak yang dianggap memahami topik atau memiliki otoritasatas persoalan yang diselidiki / topik yang dibahas, sedangkan data sekunder diperoleh melalui segala informasi yang telah dihimpun oleh berbagai pihak dalam bentuk data tersaji seperti buku/ laporan, tabel, grafik, data statistik dan penyebaran kuesioner tertutup kepada para stakeholder yang terkait dalam penelitian ini yaitu para pengguna jasa PT SPIL Cabang Pontianak.

Sedangkan data sekunder diperoleh melalui berbagai Jurnal, internet dan studi pustaka. Teknik pengumpulan data dilakukan dengan wawancara dan dokumentasi. Selanjutnya, data yang diperoleh baik primer maupun sekunder dianalisis secara kualitatif kemudian disajikan secara deskriptif. Ivanovich Agusta dalam Wibowo et al (2021) menjelaskan bahwa metode pendekatan deskriptif kualitatif adalah 
metode pengolahan data dengan cara menganalisa faktor-faktor yang berkaitan dengan objek penelitian dengan penyajian data secara lebih mendalam terhadap objek penelitian.

\section{HASIL DAN PEMBAHASAN}

\section{Sistem door to door dalam pengiriman barang}

SPIL Logistik yang biasa disebut SPIL Log adalah bagian /divisi dari kantor PT. Salam Pacific Indonesia Lines Cabang Pontianak yang menangani bagian logistik dengan penerapan sistem door to door. SPIL Logistik mempunyai tugas khusus yaitu sebagai pelayan customer yang akan melakukan pengiriman barang dengan sistem door to door. Untuk itu perusahaan selalu berusaha menghindari atau meminimalisir claim dari pelanggan, antara lain : Selalu dilakukan pengecekan container, sebelum dilakukan pengiriman barang, memastikan kontainer tidak rusak yang mengakibatkan rusaknya muatan, membuat data muatan yang terperinci, sehingga tidak terjadi kesalahan dan membingungkan pelanggan ketika pengambilan container, selalu melakukan pendekatan dan sering mendengarkan keluhan pelanggan, selalu berusaha untuk meningkatkan kinerja, apabila terjadi kekurangan, segera memperbaikinya.

Tujuan dari PT. Salam Pacific Indonesia Lines sendiri yaitu untuk meraih kepuasan pelanggan. Oleh karena itu perlu menciptakan aplikasi-aplikasi baru yang dapat memudahkan pelanggan yang akan melakukan pemesanan container, dan dapat langsung merespon dengan cepat. Terkait dengan pemanfaatan aplikasi baru, maka SPIL Log perlu melakukan sosialisasi ke pelanggan, sehingga pelanggan dapat memesan kontainer dengan mudah melalui aplikasi. Memperhatikan waktu pengantaran kontainer ke gudang pengirim, selain pemilihan kontainer yang bagus dan cocok untuk muatan. Harapan ke depan SPIL Logistik bisa mendapatkan pelanggan lebih banyak, karena sistem pemesanan kontainer yang mudah dan fast respon. Dengan adanya kegiatan tersebut diharapkan pelanggan menjadi puas dengan kinerja SPIL Logistik dan dapat menjadikan pelanggan loyal terhadap perusahaan.

Para pengusaha di Pontianak, tentu membutuhkan mitra yang dapat diandalkan untuk proses pengi riman barang dalam jumlah besar, baik secara volume maupun berat. SPIL bertekad untuk memberikan pelayanan berkelas dalam bidang shipping \& logistics port to port, port to door, door to door dalam dan luar negeri, dengan memberikan pelayanan sebagai berikut:

a. Adanya jaminan kepastian jadwal kapal. Terjadinya kerugian karena tidak dapat mengirimkan barang, disebabkan tidak adanya jadwal yang pasti dan juga kurangnya frekuensi kapal yang berlayar. SPIL menawarkan kepastian jadwal dan banyaknya pilihan waktu berlayar yang dapat membantu bisnis dan juga kebutuhan pengiriman barang.

b. Dapat memilih rute sesuai keinginan Masalah yang sering terjadi dalam pengiriman barang adalah tidak adanya pilihan rute untuk daerah tujuan pengiriman. Dapat memilih rute merupakan pilihan cerdas dalam menyiasati waktu dan biaya pengiriman, oleh karena itu SPIL hadir dengan menawarkan banyak rute yang bisa menjadi pilihan pengiriman ke seluruh wilayah Indonesia. 
c. Transaksi yang simpel. Bukan rahasia lagi bahwa prosedur dan proses pengiriman barang memerlukan waktu yang panjang dan ribet. SPIL hadir dengan aplikasi mySPIL yang didukung oleh Customer Service 24/7 (pelayanan 24 jam dalam 7 hari), siap melayani dalam hal pemesanan, pembayaran hingga pengecekan pengiriman barang.

d. Adanya jaminan keutuhan barang, sesampainya tujuan. SPIL sangat mengerti bahwa keamanan dan kualitas pengiriman adalah hal yang penting, oleh karena itu, SPIL menjamin barang terlindungi dari awal proses pengiriman hingga tiba di port/warehouse tujuan. Untuk kepentingan tersebut SPIL bekerjasama dengan Asuransi MAG sebagai solusi dan jaminan dari kebutuhan tersebut. Asuransi MAG memberikan perlindungan terhadap kehilangan dan kerusakan pada kargo, yang diakibatkan oleh bahaya laut yang terjadi selama pengangkutan kargo, baik melalui laut maupun darat. Asuransi MAG memberikan jaminan ICC A yang akan melindungi kargo dari cuaca ekstrem, kebakaran, atau bahaya laut yang dapat mengakibatkan kehilangan atau kerusakan muatan(SPILL, 2021).

Pelayanan logistik dengan sistem door to door oleh PT. Salam Pacific Indonesia Lines Cabang Pontianak saat ini berkembang begitu pesat, meliputi hampir seluruh pulau di Indonesia. Dengan menggunakan system pengiriman door to door dapat mencapai tujuan utama perusahaan yaitu untuk membuat pelanggan merasa puas. Untuk mencapai tujuan tersebut, salah satu usahanya adalah dengan membuat aplikasi MySpil untuk pelanggan yang akan booking space atau melakukan pengiriman barang.

Keuntungan menggunakan My SPIL (SPILL, 2021) :

a. Efisien dan mudah digunakan : Tampilan aplikasi mySPIL yang sederhana dapat memudahkan dan juga menghemat waktu dalam menggunakannya.

b. Beragam Fitur Layanan dalam satu Platform : mySPIL dilengkapi dengan beragam fitur untuk dapat melakukan pemesanan dengan praktis, nyaman, dan aman, misalnya :

1) Mudah mencari informasi jadwal kapal terbaru melalui fitur Check Schedule

2) Melakukan booking setiap saat, dimanapun dan kapanpun.

3) Melakukan booking menggunakan kontrak yang tersedia, maupun meminta kontrak baru yang dapat dibuat dengan mudah.

4) Monitor seluruh transaksi pengiriman Anda secara mudah dengan fitur myDashboard yang memberikan data secara real time.

5) Digitalisasi membuat segala sesuatu menjadi lebih mudah, begitu pula dengan bertransaksi di SPIL menjadi lebih mudah dengan aplikasi mySPIL yang didukung oleh PIC/Dedicated Account dan juga Call Center yang selalu sigap 24/7 melayani Anda.

c. Reward dan Bonus penggunaan : Aplikasi mySPIL juga dilengkapi reward dan bonus bagi pengguna yaitu dalam bentuk mySPIL poin dan mySPIL Referral Program.

Kemudian dalam rangka meningkatkan layanan pengangkutan darat (trucking) dengan menjalin kemitraan strategis dengan perusahaan teknologi logistik on demand,yaitu: Deliveree. Kemitraan SPIL-Deliveree adalah kombinasi yang sangat kuat. SPIL telah menjadi perusahaan pelayaran kontainer terkemuka di Indonesia selama 50 tahun terakhir. Sekarang keahlian pengiriman kami yang 
terbaik di kelasnya, mendapat dukungan dari teknologi Next-gen dari Deliveree untuk secara substansial meningkatkan operasi transportasi darat kami, mempersingkat waktu transit, dan meningkatkan transparansi pelacakan kepada pelanggan. Kemitraan SPIL-Deliveree menyatukan keterampilan yang kuat dalam operasi jalur pelayaran, pengiriman barang, dan transportasi darat yang dipasangkan dengan pemesanan, pelacakan, dan teknologi pengoptimalan kelas dunia untuk menciptakan pengalaman yang tak tertandingi bagi para pelanggan SPIL maupun Deliveree sendiri. Melalui kerjasama ini, para pengguna aplikasi mySPIL juga bisa mengakses aplikasi Deliveree untuk melakukan pemesanan pengiriman angkutan darat (trucking). Tentunya hal ini akan membawa pengaruh positif yaitu respon yang lebih cepat terhadap pasar dan permintaan customer. Secara tidak langsung juga akan meningkatkan kepuasan pelanggan.

\section{Proses outbond (bongkaran) dan inbound (muatan) dalam sistem pengiriman door to door}

Outbound logistic berarti mengangkut produk jadi dari bisnis ke pelanggan. Jaringan outbound logistic biasanya mencakup banyak mitra - produsen, distributor, pengecer, dan tim transportasi. Jika produsen menyelesaikan produk, produk akan diserahkan ke distributor atau langsung ke pelanggan melalui toko eceran. Proses distribusi outbound dikembangkan berdasarkan permintaan konsumen dengan menyediakan barang tepat waktu. Ada perusahaan yang mengirimkan produk langsung ke pelanggan berdasarkan pesanan, dan ada juga perusahaan yang mempekerjakan distributor besar dan pusat pelaksanaan yang menggunakan perusahaan telekomunikasi atau operator swasta. Mengoptimalkan logistik outbound dapat mengakibatkan kesulitan, karena bergantung pada perubahan pasar dan permintaan pelanggan secara terus menerus. Manajer juga harus mempertimbangkan jumlah jenis produk dan distributor untuk merencanakan pengiriman yang akurat. Tidak seperti inbound, logistik outbound menangani produk akhir, yang mungkin lebih rentan daripada bahan mentah, sehingga memerlukan perhatian khusus dari perusahaan PT SPIL Logistik Cabang Pontianak. Hal ini akan mengakibatkan timbulnya biaya kemasan tambahan untuk memastikan barang dan transportasi yang aman. Adapun upaya yang dilakukan oleh PT SPIL Logistik Cabang Pontianak, dalam rangka memaksimalkan outbond logistik, yaitu :

a. Menegosiasikan tarif Operator. Jika karena sesuatu sebab, PT SPIL Logistik Cabang Pontianak memerlukan kerja sama dengan operator pihak ketiga, tentu sebelumnya akan menegosiasikan tarif pengiriman, dengan mempelajari semua aspek dari kontrak pengiriman, seperti biaya tambahan atau biaya transportasi lokal yang belum diperhitungkan.

b. Menurunkan Biaya Gudang. Mengelola persediaan dapat mengurangi biaya gudang, karena sektor logistik outbound memberikan produk kepada pelanggan tepat waktu, salah satu cara utama untuk ini adalah untuk merespons perubahan permintaan dengan cepat. Agar lebih mengurangi biaya, upaya yang dilakukan adalah menggunakan sistem WMS (Warehouse Management Stock) untuk meningkatkan fleksibilitas gudang. adalah sistem yang membantu stakeholder terkait pengelolaan pergerakan barang dari/ke dalam gudang sehingga dapat mempercepat proses lead time secara otomatis, mengetahui 
semua transaksi inventory dan jumlah stok lebih cepat dan akurat secara real time. Adapun proses Outbond Logistic pada PT SPIL Logistik cabang Pontianak, dapat dilihat pada flowchart dibawah ini :

Flowchart Proses Outbond (muatan)

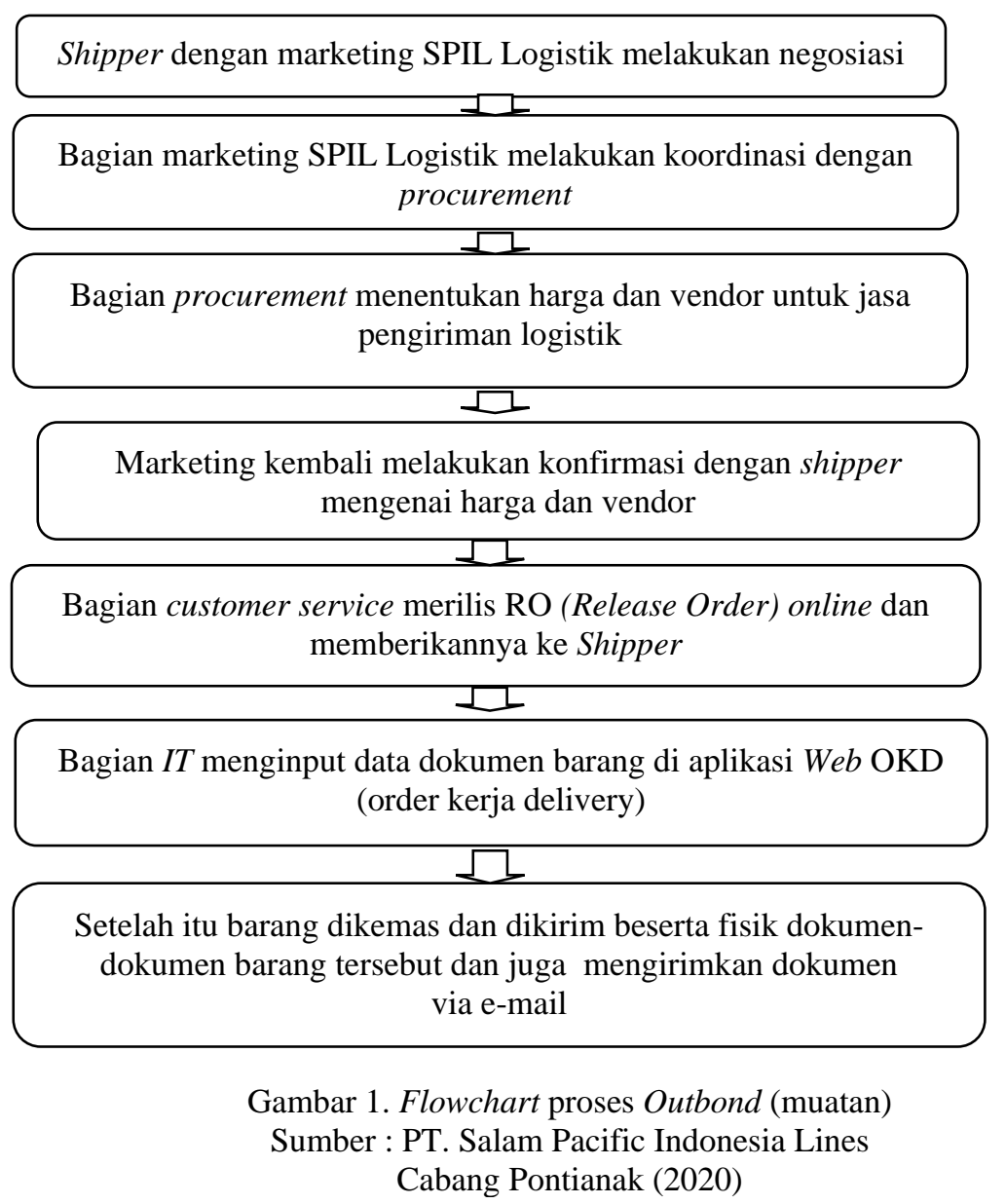

\section{Penjelasan :}

1. Pemilik barang yang akan mengirim barangnya melakukan negosiasi dengan bagian marketing PT SPIL Pontianak.

2. Selanjutnya Bagian Marketing melakukan koordinasi dengan Bagian Procurement, yang mengatur atas order muatan yang diterima.

3. Bagian Procurement selanjutnya menentukan besarnya tarif/ biaya atas pengiriman barang terebut dan sekaligus menentukan vendornya.

4. Bagian Marketing kembali melakukan konfirmasi dengan shipper mengenai tarif/ biaya dan vendor yang ditunjuk.

5. Selanjutnya bagian Costumer Service memberikan Release Order sebagai bukti telah diterimanya barang yang akan dikirim.

6. Bagian Teknologi Informasi menginput data dokumen barang yang akan diangkut, melalui aplikasi web OKD. 
7. Terakhir : barang dikirim ke pelabuhan tujuan beserta dokumennya, disamping dokumen juga dikirim via email.

Sementara Inbond Logistic (Logistik masuk) mengacu pada jaringan proses yang memindahkan barang ke dan dari bisnis. Ini mencakup setiap aspek manajemen logistik yang diperlukan untuk mengangkut, menahan, dan mengirimkan produk ke banyak pemasok. Jenis bahan yang diproses bergantung pada industri, proses logistik masuk dapat mengendalikan bahan baku produsen, komponen pemasok, dan produk jadi dalam jalur perakitan.

Dengan kata lain, proses ini mengelola kebutuhan operasional untuk mengubah bahan baku menjadi barang jadi. Manajer logistik harus menghitung persediaan bahan baku yang dibutuhkan untuk memenuhi persyaratan produksi. Tanpa distribusi yang sukses, produksi bisa kehilangan bahan penting dan penundaan dari yang direncanakan. Di sisi lain, bisnis tidak ingin memesan terlalu banyak persediaan karena hal ini dapat mengacaukan fasilitas dan menimbulkan biaya penyimpanan tambahan. Oleh karena itu, manajer perlu menyesuaikan logistik mereka dengan operasi perusahaan untuk menemukan keseimbangan antara surplus dan kekurangan. Disamping itu juga mengoptimalkan daya produksi dan mempertahankan kelancaran kerja di seluruh jaringan persediaan melalui optimasi logistik. Untuk mengoptimalkan sistem logistic inbound, manajer harus memahami pekerjaan internal setiap proses mulai dari penerimaan barang sampai pengiriman. Perusahaan kecil dapat menangani jaringan logistik dari dalam perusahaan, namun banyak perusahaan besar, sebagaimana halnya dengan PT SPIL Pontianak, didukung oleh 3PL (Third Party Logistics) yang banyak membantu pengiriman ke pelosok-pelosok daerah untuk mengantarkan barang kiriman.

Sebagai sebuah perusahaan ekspedisi selalu berlomba-lomba untuk mendapatkan hati masyarakat agar menjadi ekspedisi yang terbaik, semakin baik layanan yang diberikan, tentu masyarakat akan selalu memilih jasa pengiriman tersebut. Dengan tuntutan kecepatan, keterjangkauan daerah pada pengiriman ekspedisi, tentu ekspedisi sendiri perlu bantuan untuk melakukan pengiriman. $3 P L$ ini sangat diperlukan, jika kita harus melakukan pengiriman dari Jakarta ke Kalimantan dengan produk besok sampai, bagaimana sistem pengirimannya? Bagaimana dengan waktu singkat barang telah sampai ke daerah pelosok? Untuk itu ekspedisi harus bekerjasama dengan beberapa ekspedisi untuk melakukan pengiriman barangnya, ekspedisi tersebut yang biasa disebut $3 P L$ (Third Party Logistics). 3PL adalah sebuah perusahaan logistik yang membantu perusahaan manufaktur ataupun perusahaan logistik lainnya/ekspedisi untuk melakukan beberapa tugas yang ada di dalam supply chain management. Yang utama adalah tugas pengiriman barang, dari trucking hingga kebutuhan gudang secara end to end. Tugas logistik tentu akan memakan waktu, memakan uang dan juga sumber daya manusia untuk mengelola satu produksi, namun dengan bantuan 3PL, kita tidak perlu memikirkan kebutuhan logistik ataupun penyimpanan barang, karena semua sudah ditangani oleh 3PL. Tidak hanya perusahaan manufaktur saja yang membutuhkan partner yang mengurusi urusan logistiknya, namun beberapa perusahaan logistik ataupun ekspedisi juga saat ini membutuhkan adanya 3PL untuk menjangkau daerah terpencil hingga sebagai pembantu jika pengiriman melebihi kapasitas. Tidak hanya itu saja, perusahaan 3PL juga memiliki teknologi 
yang canggih untuk pengiriman barang, seperti live tracking dan juga sistem digital lainnya yang secara transparan dapat membantu jalannya pengiriman.

Saat ini perusahaan 3PL yang berpengaruh seperti Deliveree dan Kargo. Mereka banyak membantu para transporter atau perusahaan truk agar dapat menemukan muatan yang sesuai dengan keinginan. Caranya adalah dengan menggunakan teknologi aplikasi yang dapat mempertemukan shipper (pengirim) dengan transporter. Dengan menggunakan 3PL ini tentu menemukan muatan saat ini tidak sulit lagi, siapapun bisa mengirimkan barang hanya dengan bergabung dengan mereka.Adapun manfaat dari Menggunakan 3PL yaitu sebagai berikut

a. Menghemat Uang. Dengan menggunakan 3PL sendiri tentu akan menghemat pengeluaran kamu. Untuk bagian logistic sendiri kamu harus memiliki penyimpanan (storage), pengiriman (shipping), perangkat lunak manajemen inventaris (technologie logistics), transportasi darat dan sumber daya manusia. Untuk melengkapi hal itu kamu pun harus memiliki dana yang cukup besar dan pembangunan yang bisa dibilang masif untuk mewujudkan logistik yang baik. Dengan membuat fungsi logistik sendiri tentu fokus akan terbelah dan membuat penjualan, ataupun produksi akan terhambat. Oleh karena itu 3PL disini membantu kekosongan logistik agar dapat terpenuhi dan dapat menghemat uang kamu, dan lebih fokus terhadap penjualan, produksi, marketing dan lain-lain.

b. Menghemat Waktu dan Memberikan Expertise pada Pengiriman Logistics 3 PL sendiri sudah memiliki pengalaman dengan label pengiriman, pengemasan yang tepat, bea cukai, dan peraturan tarif yang kompetitif. Lebih canggihnya lagi, beberapa 3PL dapat mengurusi penjualan yang dimulai dari pabrik, pengawasan hingga pengiriman ke tangan konsumen. Selain itu juga, 3PL memiliki sumber daya manusia yang lebih berpengalaman di bidangnya.Tentu dengan menggunakan 3PL akan membawa perusahaan kamu ke tingkat yang lebih tinggi untuk bidang logistik, sehingga penjualan akan lebih baik dengan management service yang unggul dibandingkan perusahaan manufaktur lainnya.

c. Membantu Transporter Menemukan Shipper. Pada umumnya di Indonesia sendiri, permasalahan yang sering ditemukan adalah mencari seorang pengirim yang ingin mengirim barang dengan muatan besar dan sedang. Dibalik itu, pengirimpun juga sebenarnya mencari jasa pengiriman (transporter) yang dapat mengirimkan barangnya ke tujuan yang diminta. Perusahaan Logistik 3PL sendiri menjadi media yang mempertemukan keduanya dengan menggunakan aplikasi. Dengan begitu pengiriman dapat dilakukan dengan mudah, dan untuk transporter sendiri merupakan keuntungan untuk mendapatkan muatan tiap harinya dengan gampang sesuai yang diinginkan. Tidak hanya itu, namun biasanya 3PL di bidang ini juga menawarkan pendanaan dan juga fitur layanan yang terintegrasi dengan aplikasi, sehingga pengiriman dapat dilakukan dengan cepat hanya melalui smartphone saja.

Adapun upaya yang dilakukan PT SPIL Logistik Cabang Pontianak untuk mengoptimalkan Inbond (bongkaran), adalah sebagai berikut :

a. Membangun hubungan yang kuat dan strategis dengan pelanggan. Caranya dengan mengidentifikasi jalur pelanggan aktif dan bekerja sama dengan pengusaha armada untuk mewujudkan solusi yang saling menguntungkan. 
b. Menggunakan Sistem Manajemen Transportasi (TMS) merupakan suatu sistem yang dibuat untuk pengelolaan jasa transportasi dan ekspedisi, untuk memudahkan dalam pengelolaan penyewaan transportasi agar dapat menjangkau wilayah yang luas.

c. Banyak perusahaan menerima biaya barang yang diminta oleh vendor karena mereka tidak dapat melihat tarif pasar. Namun, sistem manajemen transportasi akan memungkinkan perusahaan mengakses biaya dinamis sesuai dengan situasi pasar saat ini, dengan demikian dapat mendapatkan tarif terbaik dan menjaga biaya minimal.

Adapun flowchart Proses Inbond (bongkaran), adalah sebagai berikut

Flowchart Proses Inbond (bongkaran)

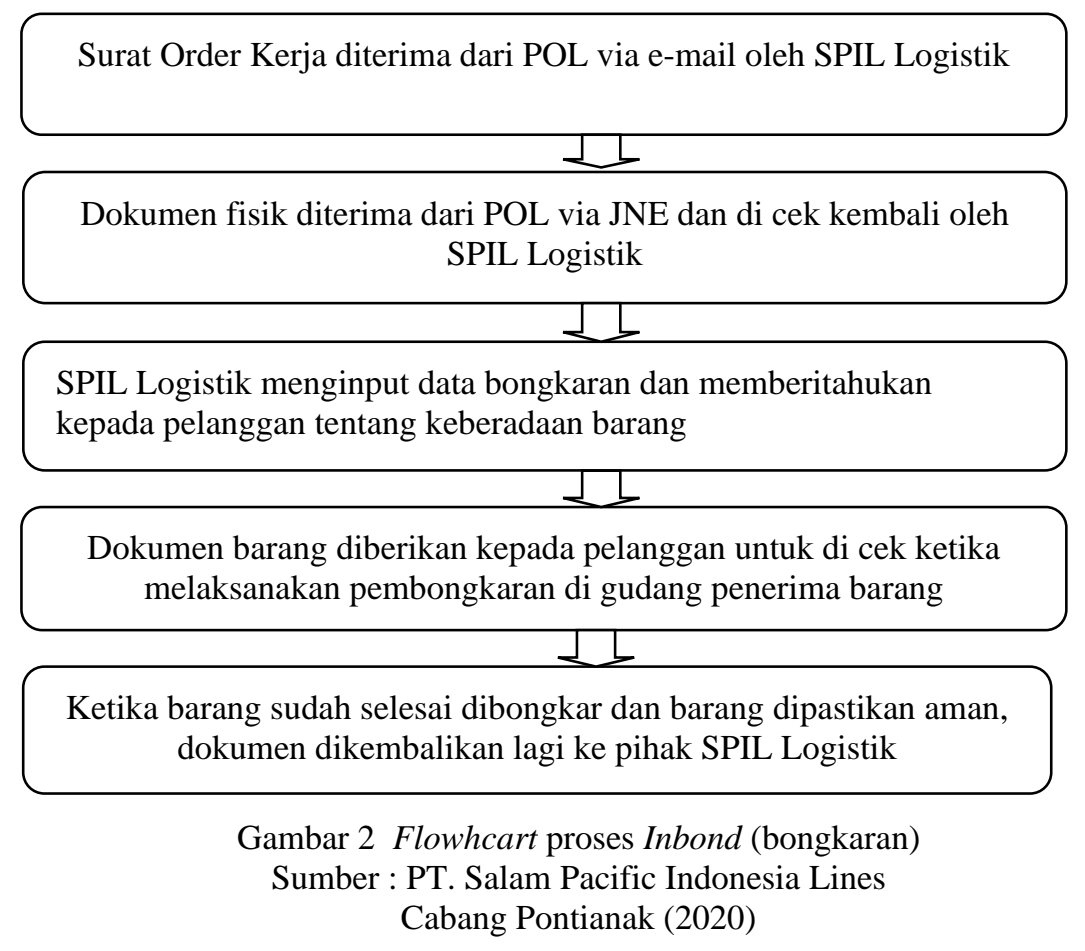

\section{Keterangan :}

1. PT SPIL Logistik cabang Pontianak, menerima order bongkaran dari pelabuhan muat (Port of Loading- POL).

2. Phisik dokumen diterima dari Port of Loading oleh PT SPIL Logistik melalui JNE, untuk selanjutnya dilakukan pengecekan/ penelitian dokumen.

3. Selesai pengecekan/ penelitian dokumen, kemudian meng 'input' data bongkaran untuk diberitahukan kepada penerima barang.

4. Pemilik barang melakukan pembongkaran, berdasarkan dokumen yang diterima dari PT SPIL.

5. Setelah selesai melakukan pembongkaran, maka oleh pemilik barang, dokumen dikembalikan lagi pada PT SPIL 


\section{SIMPULAN}

SPIL Logistik yang biasa disebut SPIL Log adalah bagian /divisi dari kantor PT. Salam Pacific Indonesia Lines Cabang Pontianak yang menangani bagian logistik dengan penerapan sistem door to door. Untuk mencapai tujuan tersebut, salah satu usahanya adalah dengan membuat aplikasi MySpil untuk pelanggan yang akan booking space atau melakukan pengiriman barang. Dalam hal pelayanan sistem door to door ada dua proses yaitu proses outbound (muatan) dan inbond (bongkaran). Proses outbond (muatan) dimulai dari dilakukannya negosiasi antara shipper (pengirim barang) dengan Bagian Marketing PT SPIL Logistik, sampai dengan dikirimnya barang beserta dokumennya dan juga mengirimkan dokumen tersebut via e-mail, sedangkan untuk proses inbond (bongkaran) dimulai dari diterimanya Surat Order Kerja dari Port of Loading (POL) via e-mail oleh SPIL Logistik, sampai diterimanya dokumen barang dari pelanggan setelah dilakukan pembongkaran.

\section{DAFTAR PUSTAKA}

Apriani, E., \& Nurasmi, N. (2020). PENGENALAN AWAL BUDAYA SUKU TIDUNG MELALUI MEDIA VIDEO ANIMASI UNTUK ANAK USIA SISTEM DOOR TO DOOR DALAM RANGKA MEMUTUS RANTAI PENULARAN COVID-19 DI SEKOLAH RA HANDAYANI. Jurnal Pengabdian Masyarakat Borneo, 4(2), 137-141.

Astriawati, N., \& Wibowo, W. (2020). Perawatan Sistem Pendingin Mesin Diesel Pada Whell Loader Komatsu Wa120-3cs. Jurnal Teknovasi: Jurnal Teknik Dan Inovasi, 7(2), 76-85.

Bowersox, D. J., \& Closs, D. J. (1997). Brazilian logistics: a time for transition. Gestão \& Produção, 4, 130-139.

Cargo, N. (2020). punya bisnis on line? Inilah keuntungan layanan door to door.

Chopra, S., Reinhardt, G., \& Dada, M. (2004). The effect of lead time uncertainty on safety stocks. Decision Sciences, 35(1), 1-24.

Coyle, B., \& Bardi, E. J. (2003). Langley. A Supply Chain Perspective, 7.

Eviani, I., \& Hidayat, Y. R. (2021). Pengaruh Sistem Pelacakan Online dan Ketepatan Waktu Pengiriman Terhadap Kepuasan Pelanggan (Studi Kasus J\&T Express Kota Baru Bekasi). JURNAL MANAJEMEN LOGISTIK, 1(1), 11-19.

Hasan, I., Syahril, A., Rahmadani, I., Irmalis, A., \& Saputra, J. (2020). Investigating the supply chain management of accessibility members of Micro and Small Enterprises (MSEs) on financing capitals in Aceh province, Indonesia. Int. $J$ Sup. Chain. Mgt Vol, 9(1), 952.

Hayati, E. N. (2014). Supply Chain Management (SCM) dan Logistic Management. Jurnal Ilmiah Dinamika Teknik.

Heragu, S. S., Cai, X., Krishnamurthy, A., \& Malmborg, C. J. (2008). Striving for warehouse excellence: Savvy material handling tools are helping in Europe. Industrial Engineer, 40(12), 43-48. 
Hutapea, T. (2019). ANALISIS KINERJA DAN PRODUKTIVITAS BONGKAR MUAT PETI KEMAS PADA PT. PELABUHAN INDONESIA I CABANG BELAWAN.

Kasengkang, R. (2016). Analisis Logistik (Studi Kasus Pada Pt. Remenia Satori Tepas-Kota Manado). Jurnal Berkala Ilmiah Efisiensi, 16(1).

Lambert, D. M. (2008). Supply chain management: processes, partnerships, performance. Supply Chain Management Inst.

Mamahit, V. S., Singkoh, F., \& Sampe, S. (2021). Pengaruh Pembangunan Infrastruktur (Jalan) Terhadap Efektivitas Distribusi Pupuk Bersubsidi Kabupaten Bolaang Mongondow Timur (Studi kasus di Kecamatan Mooat). GOVERNANCE, 1(1).

Cetak Biru Pengembangan Sistem Logistik Nasional, 7 Peraturan Presiden Republik Indonesia 1 (2012).

Pokharel, S. (2005). Perception on information and communication technology perspectives in logistics: A study of transportation and warehouses sectors in Singapore. Journal of Enterprise Information Management.

Rahardjo, M. (2011). Metode pengumpulan data penelitian kualitatif.

Rohman, S., \& Abdul, F. W. (2021). PENGARUH KUALITAS PELAYANAN DAN KETEPATAN PENGIRIMAN TERHADAP KEPUASAN PELANGGAN DALAM MENGGUNAKAN JASA PENGIRIMAN BARANG NINJA EXPRESS DI MASA PANDEMI COVID-19. Jurnal Logistik Indonesia, 5(1), 73-85.

Siregar, V. M. M. (2018). Sistem Informasi Pendataan Logistik Aktiva Tetap PT. Bank Central Asia, Tbk Kantor Cabang Pematangsiantar. Sistemasi: Jurnal Sistem Informasi, 7(3), 250-258.

Situmorang, S. H., Muda, I., Doli, M., \& Fadli, F. S. (2010). Analisis data untuk riset manajemen dan bisnis. USUpress.

SPILL, P. (2021). My SPILL.

Wibowo, W., \& Astriawati, N. (2021). Sistem Pendingin Tertutup Pada Mesin Diesel Tipe Diesel MAK 8M32 Sebagai Penggerak Utama Kapal Motor LIT ENTERPRISE. Jurnal POLIMESIN, 19(1), 28-34.

Widyanto, H. (2018). Analisis Faktor Penyebab Gagal Bayar Obligasi Syariah Sukuk Ijarah PT Berlian Laju Tanker. Majalah Ilmiah Bahari Jogja, 16(1), 65-89.

Wilson, R. (2005). Council of Supply Chain Management Professionals. 16th Annual State of Logistics Report," June. 